\title{
Kinetic Isotherm of Amoxicillin Antibiotic through Adsorption and its Removal by Electrocoagulation
}

\author{
JAYATI CHATTERJEE ${ }^{1}$, NEENA RAI ${ }^{2}$ and SANTOSH K SAR ${ }^{3}$ \\ ${ }^{1}$ Department of Chemistry, Dr. C.V. Raman University, Bilaspur, India. \\ ${ }^{2}$ Department of Chemistry, Government Engg. College, Bilaspur, India. \\ ${ }^{3}$ Department of Applied Chemistry,Bhilai Institute of Technology, Durg, India. \\ ${ }^{*}$ Corresponding author E-mail: jc.bilaspur@gmail.com
}

http://dx.doi.org/10.13005/ojc/300251

(Received: March 03, 2014; Accepted: March 31, 2014)

\begin{abstract}
Antibiotics are emerging contaminants in the aquatic environment because they have adverse effects on the aquatic life and humans. The use of antibiotics in human and veterinary medicine has a significant effect on the quality of surface and groundwater. The relevance of an electrocoagulation (EC) process for the removal of an antibiotic was selected because of its wide application, high solubility in water, high residual toxicity and an absence of biodegradability, was examined in this study. Metal hydroxides generated during EC were used to remove Amoxicillin (AMX) from aqueous solution. The knowledge regarding the removal mechanism of this substance has not yet been investigated till now. Experiments were carried out in a batch electrochemical reactor using aluminum electrodes. The removal of AMX was relatively fast and equilibrium was reached within $20 \mathrm{~min}$. The effects of the main operating parameters were examined and showed that irrespective of the initial concentration and for $\mathrm{pH}$ ranging from 3 to 10 , maximum removal efficiency remained close to $95 \%$; while a sharp decrease was recorded at $\mathrm{pH} 2$ (8\% removal). The results of this study also showed that the removal of AMX from water was strongly affected by the current intensity. The mechanism of electrocoagulation was modeled using isotherm models and showed that the Sips isotherm matched satisfactorily the experimental data, suggesting monolayer coverage of adsorbed molecules and assumed a quasi-Gaussian distribution energy owing to the high correlation also found for the Toth model. In addition, adsorption kinetic studies showed that the EC process followed a pseudo-second-order kinetic model at the various current densities, as when the $\mathrm{pH}$ and initial antibiotic concentrations were considered.
\end{abstract}

Key words: Adsorption, Electrocoagulation, Amoxicillin, Kinetics, Isotherm.

\section{INTRODUCTION}

Amoxicillin is a moderate-spectrum (3lactam antibiotic used to treat bacterial infections caused by susceptible microorganisms. From an environmental engineering point of view, pharmaceuticals such as antibiotics are a new group of man made chemicals of concern entering our environment at concentration such that the health effects are unknown. Research has begun 
to determine the concentrations of antibiotics in the environment, and from this information the health effects to humans and animals may be estimated by toxicologists. Traditionally, the impact of chemical pollution has focused almost exclusively on the conventional priority pollutants. However, the growing use of pharmaceuticals worldwide, classified as the so-called emerging pollutants, has become a new environmental problem, which has raised great concern among scientists in the last few years. More than 3,000 chemical products are used in human and veterinary medicine. The use of antibiotics in human and veterinary has a significant effect on the quality of surface and ground water. Among veterinary pharmaceuticals, antibiotics are widely prescribed. At present, it has been reported that AMXs have been found in soils, surface water and groundwater. Frequent application of amoxicillin antibiotics has given cause for concern about increased antibiotic resistance of microorganisms in the terrestrial as well as aquatic environment and the effect of antibiotics on plant and aquatic growth. Amoxicillin is an antibiotic active against a wide range of Gram-positive, and a limited range of Gram-negative organisms. Amoxicillin acts by inhibiting the synthesis of bacterial cell walls. It inhibits cross-linkage between the linear peptidoglycan polymer chains that make up a major component of the cell wall of Gram-positive bacteria. It is usually the drug of choice within the class because it is better absorbed, following oral administration, than other beta-lactam antibiotics. Amoxicillin is susceptible to degradation by (3lactamase-producing bacteria, and so may be given with clavulanic acid to decrease its susceptibilityThe presence of AMX and other antibiotics in natural environments can cause bacteria to acquire and transmit antibiotic-resistant genes, which potentially threatens ecosystem functions and human health. Even low concentrations of pharmaceuticals released from the environmental matrix into water can pose serious environmental damages. Thus, it is of great importance to develop some efficient and cost effective treatment technologies to remove such compounds. Various techniques such as ozonation , photo-Fenton process, photo-electro-catalytic degradation, ion exchange and other processes have been employed for the removal of antibiotics from water. Among these available methods, adsorption is a widely used effective technology for the treatment of low concentration antibiotics. Recently, adsorption of antibiotics on sorbents based on metal or metal oxides such as montmorillonite, hydrous oxides of aluminum and iron were reported. The present study proposes an electrocoagulation (EC) process for the removal of tetracycline, which was selected because of its wide application, high solubility in water, high residual toxicity and its absence of biodegradability. Recent research has demonstrated that electrocoagulation offers an attractive alternative method for treating water. EC treatment is characterized by simple and easy operated equipment, short operation time, no addition of chemicals and low sludge production. Iron or aluminum is generally employed as a sacrificial electrode material in EC process but other anodes like magnesium alloy and aluminium alloy can also be used. The dissolved metal ions, at an appropriate $\mathrm{pH}$, can form a wide range of hydro complex species and metal hydroxides that destabilize and aggregate the suspended particles or precipitate and adsorb dissolved contaminants. The anodic and cathodic reactions for aluminium electrodes can be written as:

At the anode

$\mathrm{Al}(\mathrm{s}) \rightarrow \mathrm{Al}^{3+}(\mathrm{aq})+3 \mathrm{e}-$

At the cathode

$3 \mathrm{H}_{2} \mathrm{O}+3 \mathrm{e}^{-} \rightarrow 3 / 2 \mathrm{H}_{2}(\mathrm{~g})+3 \mathrm{OH}^{-}$

The generated $\mathrm{Al}(\mathrm{aq}) 3+$ ions combine with hydroxyl ions to form the metal hydroxides which are partly soluble in the water under definite $\mathrm{pH}$ values. $\mathrm{Al}^{3+}$ and $\mathrm{OH}$ - ions generated by electrode reactions (1) and (2) react to form various monomeric species such as $\mathrm{Al}(\mathrm{OH})^{2+}, \mathrm{Al}(\mathrm{OH})_{2}{ }^{+}$, $\mathrm{Al} 2(\mathrm{OH}) 2^{4+}, \mathrm{Al}(\mathrm{OH}) 4^{-}$, and polymeric species such as Al6 $(\mathrm{OH}) 15^{3+}$, Al7 $(\mathrm{OH}) 17^{4+}$, Al8 $(\mathrm{OH}) 20^{4+}$, Al13O4(OH)24 ${ }^{7+}$, Al13(OH) $34^{5+}$, which transform finally into $\mathrm{Al}(\mathrm{OH}) 3(\mathrm{~S})$ according to complex precipitation kinetics.

$\mathrm{Al}^{3+}+3 \mathrm{H}_{2} \mathrm{O} \rightarrow \mathrm{Al}(\mathrm{OH})_{3}+3 \mathrm{H}^{+}$

The polymeric aluminum complexes can have both positive and negative charges capable of attracting the opposite charge of polluting species and remove them from the solution. 
Electrocoagulation is a complex and interdependent process strongly dependent on the chemistry of the aqueous medium. The electrolyte $\mathrm{pH}$ plays an important role in the separation of suspended particles; at low $\mathrm{pH}$ the separation is dominated by precipitation while adsorption dominates at high electrolyte $\mathrm{pH}$. The $\mathrm{Al}(\mathrm{OH}) 3(\mathrm{~s})$ formed "sweep flocs" have large surface areas which is beneficial for a rapid adsorption of soluble organic compounds and trapping of colloidal particles. Finally, these flocs can be easily removed from aqueous medium by sedimentation or $\mathrm{H}_{2}$ flotation. In this study, a series of batch experiments were conducted. The removal efficiency was investigated by a series of experiments under different experimental conditions such as reaction time, solution $\mathrm{pH}$, initial amoxicillin concentration and current intensity. To our knowledge, no report is available in the literature dealing with the reduction of $\mathrm{AMX}$ concentration in water using the EC process.

\section{Theoretical part \\ Electrocoagulation kinetics}

The pollutant is generally adsorbed at the surface of the flocs electrochemically generated, following two consecutive separate processes: (i) An electrochemical process through which the metal flocs are generated; (ii) followed by a physicochemical process, namely adsorption on the surface of the flocs. The removal of pollutant is similar to conventional adsorption except the generation of coagulants. The electrode consumption can be estimated according to Faraday's Law and the amount of flocs generated can be stoichiometrically estimated. The formed aluminum floc traps the pollutant present in the solution by adsorption mechanism: From this, pollutant removal can be modeled by adsorption phenomena and the amount of adsorbed pollutant is:

$$
q a=V\left(C_{0}-C t\right) / M
$$

Where qa is the amount of amoxicillin (AMX) adsorbed per gram of medium $(\mathrm{mg} / \mathrm{g}), V$ is the volume of solution (L), $M$ is the weight of electrode dissolved $(\mathrm{g})$; $C O$ and $C t$ are the initial concentration and the concentration of $\mathrm{AMX}$ at any time $\mathrm{t}(\mathrm{mg} / \mathrm{L})$, respectively. In order to investigate the mechanisms of the adsorption process, various kinetic models: pseudo-first-order, pseudo-secondorder, Fractional Power and Elovich models were applied to describe the adsorption kinetics onto aluminum hydroxides. The most accurate model was selected according to the linear regression correlation coefficient values, R2. The pseudo-first order kinetic model can be given as:

$\mathrm{dq} / \mathrm{dt}=\mathrm{K}_{1}(\mathrm{qe}-\mathrm{qt})$

Where $K 1$ ( $\min -1)$ is the constant rate of adsorption, $q t$ and $q e$ are the adsorbed amounts at a given time $t$ and at equilibrium $(\mathrm{mg} / \mathrm{g})$ respectively. After integration between 0 and a given time $t$, it comes:

$\ln (q e-q t / q e)=-K_{1} t$

Which can be rearranged to give:

$\ln (q e-q t)=\operatorname{lnqe}-K_{1} t$

The pseudo second-order model kinetic equation is :

$d q / d t=K_{2}(q e-q t)^{2}$

Where $K 2$ is the rate constant of the pseudo-second order equation ( $\mathrm{g} / \mathrm{mg} / \mathrm{min})$. Integration leads to:

$t / q t=1 / K_{2} q e^{2}+t / q e$

The adsorption of AMX onto aluminum hydroxides was also examined by Elovich and Fractional Power. The linearized method was used to determine the parameters of the kinetic models.

The Elovich model kinetic equation is:

$q t=(1 / 2) \cdot \ln \pm /^{2}+(1 / 2) \ln t$

The Elovich model was originally developed to describe the kinetics of heterogeneous chemisorptions of gases on solid surfaces. It has been used to describe the kinetics of sorption/desorption of various chemicals on solid phases. A plot of (qt) vs. (Int) should give a linear relationship if the Elovich model is applicable, with a slope of $1 / b$ and an intercept of $1 / b \ln (a b)$. 
The Fractional Power or Power Function model kinetic equation is:

$$
\mathrm{qt}=\mathrm{Ktn}
$$

with $v$ a positive constant $(<1)$ and $K$ a constant. The kinetic parameters were obtained from the plot $\ln (q t)$ vs $\ln (t)$, with a slope and an intercept of $\ln K$. Equation 11 is empirical, except for the case where $v=0.5$; then Eq. 11 becomes similar to the Weber-Morris model. Equation 11 and various modified forms have been used by a number of researchers to describe the kinetics of solid phase sorption/desorption and chemical transformation processes.

\section{Adsorption isotherm}

Since the removal of pollutant is similar to conventional adsorption, except the generation of coagulants, adsorption isotherm models can be extended to describe experimental isotherm data and identify the mechanism of the adsorption process. Isotherm models with two and three parameters have been therefore considered to establish the relationship between the amounts of amoxicillin adsorbed onto the aluminum hydroxides and its equilibrium concentration in the aqueous solution containing amoxicillin antibiotic. The general forms of both these models were described as follows.

The Langmuir equation:

$\mathrm{Ce} / q \mathrm{q}=1 / \mathrm{b}+q 0 / b \mathrm{Ce}$

Where $b(\mathrm{~L} / \mathrm{mg})$ is the binding constant and $q O(\mathrm{mg} / \mathrm{g})$ refers the maximum adsorption capacity, evaluated by potting the $\mathrm{Ce} / \mathrm{qe}$ against $\mathrm{Ce}$.

The Freundlich isotherm:

In qe $\ln K f+1 / \mathrm{n} \ln C e$

Where $K f$ and $n$ are the constants which give adsorption capacity and intensity respectively.

\section{The Sips equation}

In the Sips model (eq.14), qe and Ce are the adsorption capacity at equilibrium and the equilibrium concentration, $q 0$ represents the maximum adsorption capacity, $b$ the adsorption equilibrium constant and $n$ the dissociation parameter. If $n=1$, the Sips model reduces to the Langmuir model.

$q e=q_{0} b C e^{n} / 1+b C e^{n}$

\section{The Toth equation}

The Toth model is derived from potential theory and is applicable to heterogeneous adsorption. This isotherm (Eq. (15)) presupposes a quasi-Gaussian energy distribution. Most sites have an adsorption energy lower than the peak or maximum adsorption energy.

$q e=q 0 \mathrm{Ce} /\left(b+C e^{m}\right)^{1 / m}$

\section{MATERIALS AND METHODS}

\section{Chemical and reagents}

Amoxicillin hydrochloride (>95\%) was obtained from Sigma-Aldrich (India). The molecular structure and pKa of AMX are shown in Fig.1. AMX could have different charges on different sites depending on the $\mathrm{pH}$. According to the speciation of $\mathrm{AMX}$ under various $\mathrm{pHs}$, when solution $\mathrm{pH}$ is below 3.3, AMX exists as a cation, +00 , due to the protonation of the organic group. At $\mathrm{pH}$ between 3.3 and 7.7 , the zwitterion form, +-0, predominates due to the loss of a proton from the phenolic diketone moiety. At solution $\mathrm{pH}$ greater than 7.7, a monovalent anion +--, or a divalent anion 0--, from the loss of protons from the carbonyl system and phenolic moiety prevail.

\section{Experiments}

Experiments were carried out in a batch electrochemical reactor of $500 \mathrm{~mL}$ capacity (Fig.2) with Aluminum / Aluminum as sacrificial anode of $28.5 \mathrm{~cm} 2$ of submerged area. The electrode distance between anode and cathode was maintained constant at a value of $2 \mathrm{~cm}$ during electrolysis. A direct current was supplied by a DC regulated power source. Proper agitation was provided to maintain an uniform concentration inside the cell. A stock solution was prepared by dissolving an appropriate quantity of amoxicillin in distilled water. The concentration of the supporting electrolyte was adjusted by adding $\mathrm{KCl}$, and the amoxicillin solutions were characterized by measuring their 
conductivity, which was found to be $1.2 \mathrm{mS} / \mathrm{cm}$. The $\mathrm{pH}$ of the solution was adjusted by adding diluted $\mathrm{HCl}$ or $\mathrm{NaOH}$. The sample was collected at every $30 \mathrm{~s}$ interval and then analyzed by UV-Vis spectroscopy. Experiments have been duplicated and the error was found to be below $4 \%$.

\section{Amoxicillin measurement}

Antibiotic concentrations were quantified by UV/Vis spectroscopy (UV-Vis - Systronics Spectrophotometer). Amoxicillin absorbance was measured at $360 \mathrm{~nm}$. This wavelength is an isobestic point for this antibiotic.

\section{RESULTS AND DISCUSSION}

\section{Effect of the operating parameters Effect of the contact time}

Fig. 3 shows the effect of the shaking time on the removal of $\mathrm{AMX}$ by electrocoagulation process. High removal rates of AMX were observed at the onset; and then plateau values were gradually reached within $15 \mathrm{~min}$. The residual $\mathrm{AMX}$ concentration versus time showed a single, smooth and continuous curve until reaching saturation (Fig.3), suggesting possible monolayer coverage of AMX on the surface of the sorbent produced in situ.

\section{Effect of the current intensity}

In all electrochemical process, the current density is the most important parameter for controlling the reaction rate within the electrochemical reactor. The current density is expected to exhibit a strong effect on EC, especially on the kinetics of removal, shortening the treatment. This is ascribed to the fact that at high current density, the extent of anodic dissolution of aluminum increases, resulting in a greater amount of precipitate for the removal of pollutants.

Moreover, bubble generation rate increases with increasing current intensity. These effects are both beneficial for high pollutant removal by $\mathrm{H} 2$ flotation. To investigate the effect of the current density, a series of experiments were performed using $50 \mathrm{mg} / \mathrm{L} \mathrm{AMX}$ containing solution, at $\mathrm{pH}=6$, for current intensities varying from 0.1 to $0.8 \mathrm{~A}$ (Fig.4). The removal efficiency of AMX increased rapidly up to $98 \%$ for a current intensity of $0.3 \mathrm{~A}$ after only 6 min (Fig.4). It can also be observed that when the current intensity increased, the operating time decreased. For example, when the current intensity was increased from 0.1 to $0.8 \mathrm{~A}$, the retention time of $A M X$ solution in the electrocoagulation unit was shortened from $15 \mathrm{~min}$ to $5 \mathrm{~min}$. This means that the electrocoagulation equipment can be almost three times smaller for 0.8 A current intensity. These results have to be related to the increase of the amount of $\mathrm{Al} 3+$ cations released by the anode and hence the increase of $\mathrm{Al}(\mathrm{OH}) 3$ particles. However, the difference between the curves corresponding to different current intensity became small when it was higher than 0.3 A. An optimum current density can therefore be defined. For the experimental conditions of Fig.4, optimal current seemed therefore to be equal to $0.3 \mathrm{~A}$

\section{Effect of the $\mathrm{pH}$}

It has been established that the $\mathrm{pH}$ is one of the most significant factors affecting the performance of the electrochemical process, particularly on the performance of the electrocoagulation process. To evaluate its effect, a series of experiments were performed, using 50 $\mathrm{mg} / \mathrm{L}$ amoxicillin for initial $\mathrm{pH}$ in the range 2 to 10 . As illustrated in Fig.5, the removal efficiency of amoxicillin remained constant and close to $99 \%$ for $\mathrm{pH}$ in the range 4 to10, and decreased to $10 \%$ for $\mathrm{pH}$ 2. The effect of $\mathrm{pH}$ can be explained considering aluminum and $\mathrm{AMX}$ equilibrium related to $\mathrm{pH}$. At low $\mathrm{pH}$, such as $2-3$, cationic monomeric

Fig.1: Molecular structure of Amoxicillin AMX 
species $\mathrm{Al} 3+$ and $\mathrm{Al}(\mathrm{OH}) 2$ + predominated. Furthermore when $\mathrm{pH}$ was below 3.3, AMX existed as a cation, +00 , due to the protonation of dimethyl ammonium group, so the electrostatic repulsion between the cationic monomeric species ( $\mathrm{Al} 3+$ and $\mathrm{Al}(\mathrm{OH}) 2+)$ hindered the AMX adsorption, resulting in a low efficiency. According to the speciation of $\mathrm{AMX}$ under various $\mathrm{pHs}$, at $\mathrm{pH}$ between 3.3 and 7.7, AMX exists as zwitterion +-0, due to the loss of proton from the phenolic diketone moiety. On the other hand, when the $\mathrm{pH}$ was between 4 and 10 , the $\mathrm{Al} 3$ +and $\mathrm{OH}$-ions generated by the electrode

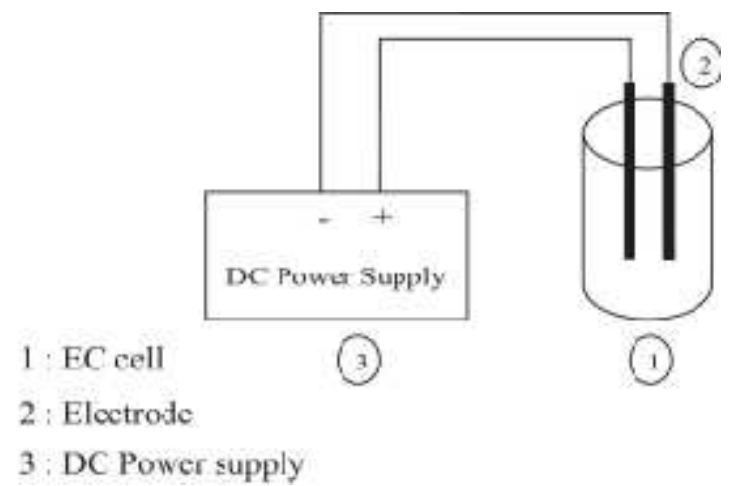

Fig. 2: Schematic experimental setup of the electrocoagulation cell

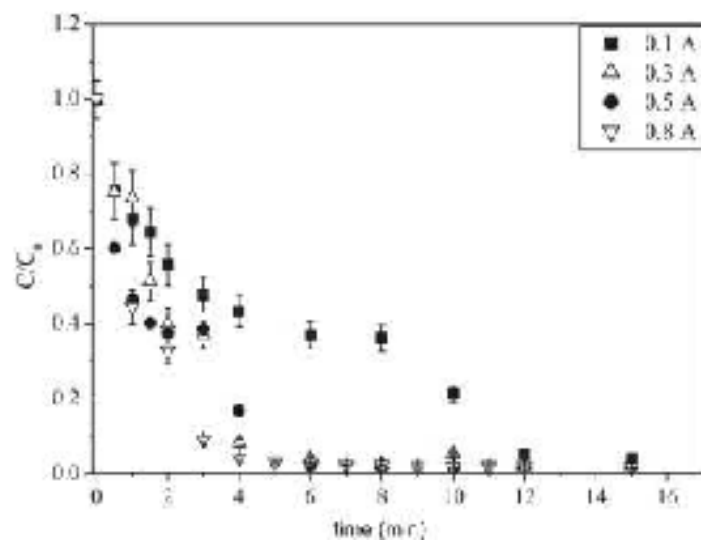

Fig. 4: Effect of the current intensity on the removal of AMX by electrocoagulation process (conditions: initial concentration of $A M X, 50 \mathrm{mg} / \mathrm{L}$ volume of solution medium, $500 \mathrm{~mL}$; temperature, $20 \pm 1^{\circ} \mathrm{C}$; agitation rate, $400 \mathrm{tr} / \mathrm{min}$, conductivity $1.2 \mathrm{~ms} / \mathrm{cm}$ ) react to form various monomeric species such as $\mathrm{Al}(\mathrm{OH}) 2+, \mathrm{Al}(\mathrm{OH}) 22+$ and polymeric species such as Al6 $(\mathrm{OH}) 153+, \mathrm{Al}(\mathrm{OH}) 74+, \mathrm{Al} 13(\mathrm{OH}) 345+$ which are finally converted into insoluble amorphous $\mathrm{Al}(\mathrm{OH}) 3(\mathrm{~S})$ through complex polymerization/precipitation kinetic. The best removal of AMX was accomplished by charge neutralization and adsorption in the presence of the species mentioned above. For Zhou et al., the hydrolytic species such as $\mathrm{Al}(\mathrm{OH}) 3$ with a large surface area and amorphous structure are positively

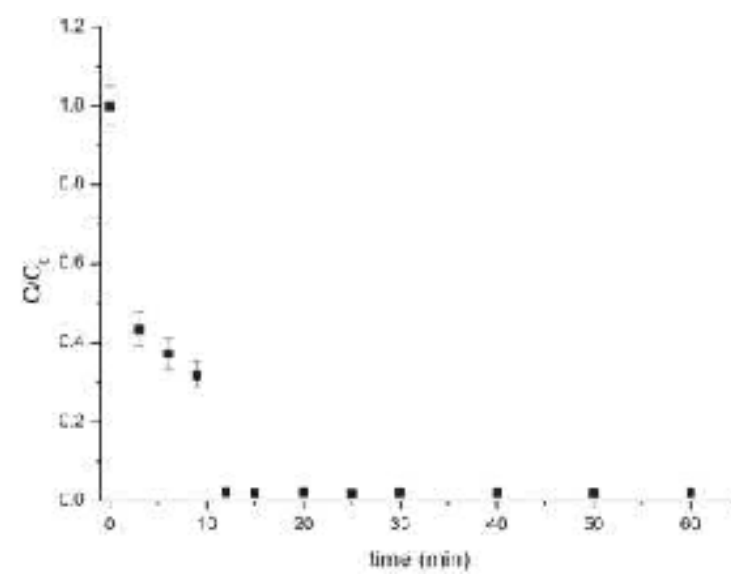

Fig. 3: Effect of the contact time on the removal of AMX by electrocoagulation process (conditions initial concentration of AMX, $50 \mathrm{mg} / \mathrm{L}$; volume of solution medium, $500 \mathrm{~mL}$; temperature, $20 \pm 1^{\circ} \mathrm{C}$; agitation rate, $400 \mathrm{tr} / \mathrm{min}$, conductivity $1.2 \mathrm{~ms} / \mathrm{cm}$ ).

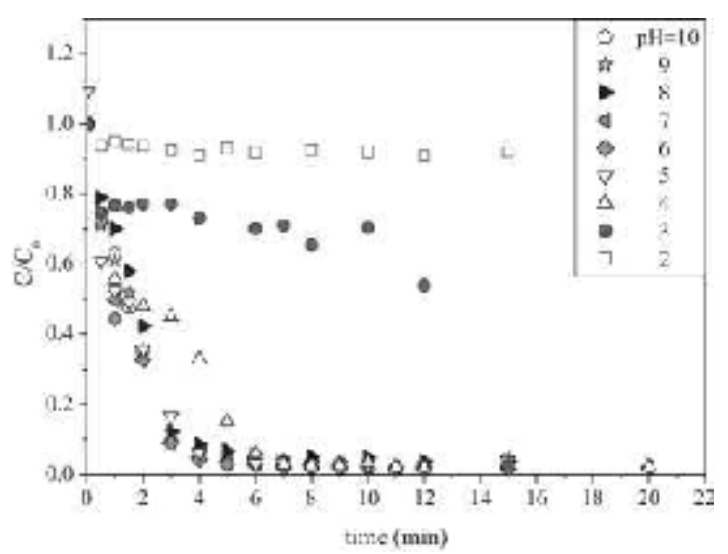

Fig.5. Effect of $\mathrm{pH}$ on the removal of AMX by electrocoagulation process (conditions: initial concentration of $A M X, 50 \mathrm{mg} / \mathrm{L}$; volume of solution, $800 \mathrm{~mL}$; temperature, $20 \pm 1^{\circ} \mathrm{C}$; agitation rate, $400 \mathrm{tr} / \mathrm{min}$, conductivity $1.2 \mathrm{~ms} / \mathrm{cm}$ ) 
charged and are therefore strongly adsorbed onto the organic anionic particle and become insoluble by hydrolyzed cationic species such as $\mathrm{Al}(\mathrm{OH}) 2+$ and hence are more strongly adsorbed on negative surface than the free hydrated metal ion. At $\mathrm{pH}$ greater than 7.7, AMX prevails as a monovalent anion, +- or a divalent anion 0-, from the loss of protons from the carbonyl system and phenolic diketone moiety. The high removal efficiency can be assigned to the double effects of the attracted force between the cationic species of $\mathrm{Al} 3+$ and anionic species of $\mathrm{AMX}$ and the adsorption of this latter onto $\mathrm{Al}(\mathrm{OH}) 3$, which presents a large surface area. These flocs are active leading to a rapid adsorption of soluble organic compound (and trapping of colloidal particle) and are easily separated from aqueous medium by sedimentation or $\mathrm{H} 2$ flotation. The surface complexes of zwitterionic species of AMX were previously suggested by Figueroa et al. as the major contributor to the adsorption mechanism of a kaolinite, montmorillonite. These results were also reported by Chen et al who studied the adsorption and transformation of antibiotics onto aluminum oxide.

\section{Effect of the initial AMX concentration}

The initial concentration provides an important driving force to overcome all mass transfer resistances of solutes between the aqueous and the solid phase. The effects of the initial concentration (10-300 $\mathrm{mg} / \mathrm{L})$ were investigated at

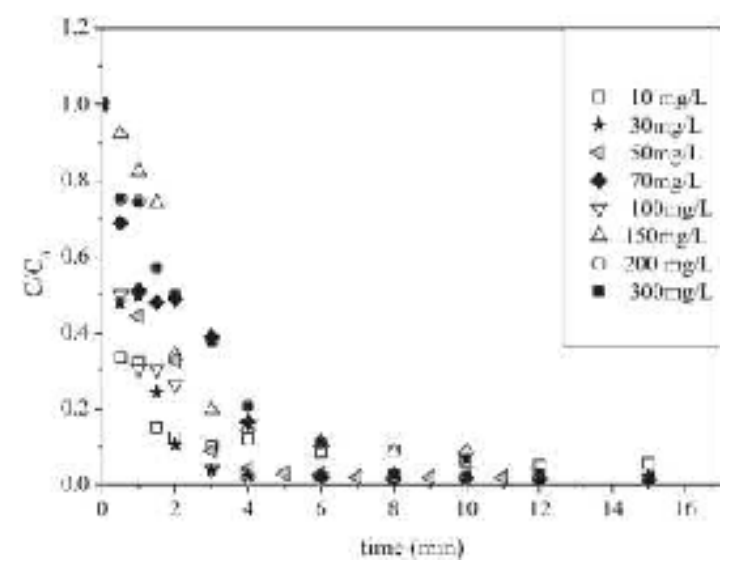

Fig. 6. Effect of the initial AMX concentration on its removal by electrocoagulation process (conditions: volume of solution, $500 \mathrm{~mL}$; current intensity, $0.8 \mathrm{~A}$; temperature, $20 \pm 1^{\circ} \mathrm{C}$; stirring rate, $400 \mathrm{tr} / \mathrm{min}$, conductivity $1.2 \mathrm{~ms} / \mathrm{cm}$ ) constant current intensity 0.8 A with $1.25 \mathrm{~g} / \mathrm{L} \mathrm{KCl}$ in each experiment. The temperature of $\mathrm{AMX}$ solution was maintained at $20^{\circ} \mathrm{C}$ and the EC experiments

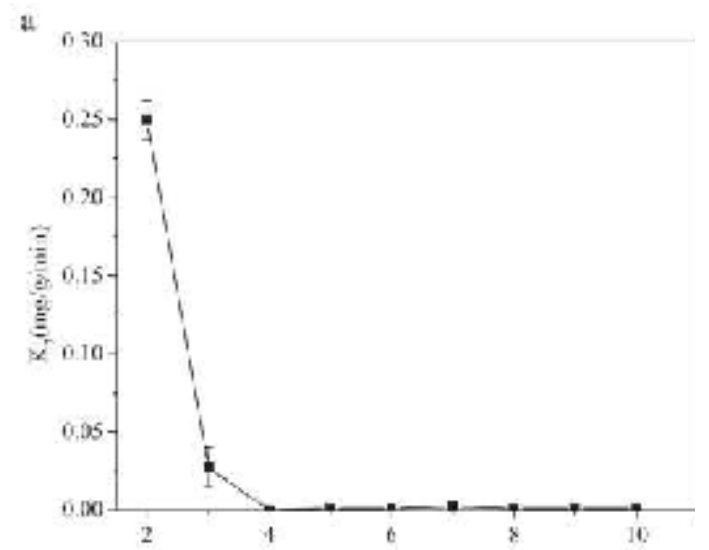

b
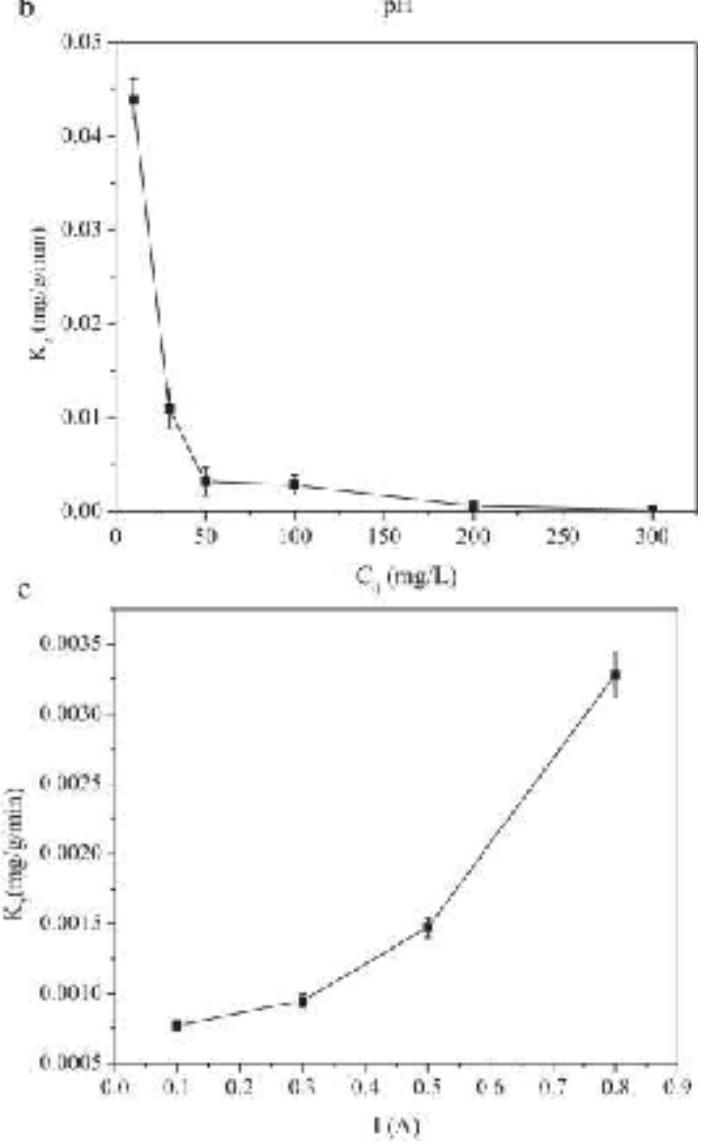

Fig. 7: Effect of pH (a) initial concentration (b) and current intensity (c) on the rate constant $\mathrm{K} 2$ 
were run each time for about $15 \mathrm{~min}$. The effect of the initial concentration on the removal yield is displayed in Fig.6, showing that the removal efficiency (RE) decreased almost linearly for increasing AMX concentrations. The highest RE $(96.5 \%)$ was obtained after only $2 \mathrm{~min}$ at $10 \mathrm{mg} / \mathrm{L}$, while the lowest RE $(50 \%)$ was obtained at 300 $\mathrm{mg} / \mathrm{L}$. Lower RE at higher AMX concentration was caused by a lower amount of coagulant, $\mathrm{Al}(\mathrm{OH}) 3$ species, which became therefore limiting.

\section{Isotherm modeling}

Analysis of the experimental adsorption data was carried out by considering the Langmuir, Freundlich, Sips and Toth isotherms. The applicability of these isotherms was compared using the correlation coefficient R2. The values for the constants $q 0, b, K f, n$ and $m$ of the isotherms are collected and based on the $R 2$ values, it can be noticed that the considered adsorption isotherms matched experimental data in the following increasing order: Sips > Toth > Langmuir > Freundlich isotherms. The above order revealed that the equilibrium data are better fitted by threeparameter models than two-parameter models. The Sips model was found to be the most relevant to represent equilibrium data, showing that adsorption was heterogeneous and assumed a quasiGaussienne distribution energy owing to the high $\mathrm{R} 2$ value also found for the Toth model.

\section{Kinetic studies}

Pseudo-first, pseudo-second, Elovich and fractional Power models have been considered to describe experimental data and the corresponding correlation coefficients are given in Table 2. As shown, for all studied parameters the correlation coefficients for the first-order, Elovich and Power function kinetic models were relatively lower than those obtained for the second-order kinetic model for the various current densities, $\mathrm{pH}$ and initial AMX concentrations considered. These results indicate that the second-order kinetic model can be suitably applied to predict the amoxicillin adsorption process onto aluminum hydroxides. This model supposes that two reactions either in series or in parallel occur; the first one is fast and reaches equilibrium quickly and the second is a lower reaction that can continue for a long period of time. It has been observed above that the operating parameters have a significant influence on the rate constant $K 2$ of the pseudosecond order model (Eq.9). Fig.7a shows the influence of $\mathrm{pH}$ on the rate constant. It can be ascertained that the rate constant remained constant for $\mathrm{pH}$ values in the range of $4-10$, similarly to the $\mathrm{pH}$ effect on $\mathrm{AMX}$ removal yields. The effect of the initial concentration on the rate constant shows that the reaction rate constant $(K 2)$ decreased significantly for increasing initial $A M X$ concentrations (Fig.7b). This may be due to the fact that for a given charge, the number of hydroxides flocs generated was insufficient and an increase in the ratio of the initial concentration to the amount of flocs generated resulted in a reduction of the yield of AMX removal. The effect of the current intensity on the rate constant shows an increase for increasing current intensities (Fig.7c). This may be explained by the fact that for a given amount of pollutant, the amount of $\mathrm{Al}(\mathrm{OH}) 3$ generated increased with the current intensity.

\section{CONCLUSION}

This work was a first step to improve the knowledge regarding the process removal by electrocoagulation with aluminum electrodes. The EC method applied in this study provided a sensitive, rapid and reliable technique for the removal of $\mathrm{AMX}$. The use of aluminum as sacrificial electrodes in the treatment of synthetic AMX solutions by electrocoagulation has been found to be dependent on $\mathrm{pH}$, current intensity and initial concentration. By applying linear methods, the mechanism of EC was modeled using pseudo-first, Elovich, Power Function and pseudo-second order models and it was shown that the EC kinetic followed pseudo-second order kinetic and that the reaction rate constant was influenced by the operating parameters. The metal hydroxides generated by EC can efficiently remove amoxicillin by adsorption, and the EC process was modeled using adsorption isotherm models, showing that the Sips model accurately described experimental data. The results obtained in this study appear promising for the application of EC technology for the treatment of waters loaded with antibiotics, such as amoxicillin $(A M X)$. For this purpose, they should be subsequently confirmed on real effluent. 


\section{Nomenclature}

$\mathrm{a}$ and $\mathrm{b}$ constants in the Elovich model

$b \quad$ the binding constant in the Langmuir model (L/mg)

CO the initial AMX concentration ( $\mathrm{mg} / \mathrm{L})$

$\mathrm{Ca} \quad \mathrm{AMX}$ concentration at a given time $\mathrm{t}(\mathrm{mg} / \mathrm{L}) \quad q 0$

$K 1$ the rate constant of adsorption ( $\mathrm{min}-1)$

K2 the rate constant of the pseudo-second order $n$ equation $(\mathrm{g} / \mathrm{mg} / \mathrm{min})$

$K f$ refers to the adsorption capacity in the Freundlich model
$K, \mathrm{n}$ constants in the Fractional Power model

$M \quad$ the mass of electrode dissolved $(\mathrm{g})$

qe the adsorbed amount at equilibrium $(\mathrm{mg} / \mathrm{g})$

qt the amount of amoxicillin (AMX) adsorbed per gram of medium $(\mathrm{mg} / \mathrm{g})$

refers to the maximum adsorption capacity $(\mathrm{mg} / \mathrm{g})$

refers to the intensity value in the Freundlich model

Constant in the Toth model

the volume of solution (L)

\section{REFERENCES}

1. Liu, H., Wang, H., Sunderland, V.B., "An isocratic ion exchange HPLC method for the simultaneous determination of flucloxacillin and amoxicillin in a pharmaceutical formulation for injection" J. Pharm. Biomed. Anal, 2005.37(2), 382-395,

2. Wang, P., Qi, M., Sun, Y., Yang, J., "A liquid chromatographic method for simultaneous determination of amoxicillin sodium and sulbactam sodium in a combination formulation" J. Pharm. Biomed. Anal, 2004., 36(3), 565-569,

3. Aghazadeh, A., Kazemifard, G., "Simultaneous determination of amoxycillin and clavulanic acid in pharmaceutical dosage forms by LC with amperometric detection" J. Pharm. Biomed. Anal, 2001., 25(2), 325-329,

4. Abounassif, M.A.., Abdel-Moety, E.M., Mohamed, M.E., Gad-Kariem, R.A., "Liquid chromatographic determination of amoxycillin and clavulanic acid in pharmaceutical preparations" J. Pharm. Biomed. Anal, 1991. 9(9), 731-735,

5. Menelaou, A., Somogyi, A.A., Barclay, M.L., Bochner, F., "Simultaneous quantification of amoxycillin and metronidazole in plasma using high-performance liquid chromatography with photodiode array detection" J. Chromatogr. B Biomed. Sci. Appl, 1999.,731(2), 261-266,

6. Tsou, T. L., Wu, J.R., Young, CD., Wang, T.M., "Simultaneous determination of amoxycillin and clavulanic acid in pharmaceutical products by HPLC with beta cyclodextrin stationary phase" J. Pharm. Biomed. Anal, 1997. 15(8), 1197-1205,

7. Wang, P., Qi, M., Sun, Y., Yang, J., "A liquid chromatographic method for simultaneous determination of amoxicillin sodium and sulbactam sodium in a combination formulation" J. Pharm. Biomed. Anal, 2004.,36(3), 565-569,

8. Indrayanto, G., Sa, T.K., Widjaja, S., "Simultaneous determination of amoxicillin trihydrate and clavulanate potassium in pharmaceutical preparations by thin-layer chromatography/densitometry" J.AOACInt, 2000., 83(6), 1493-1496,

9. Pajchel, G., Pawlowski, K., Tyski, S., "CE versus LC for simultaneous determination of amoxicillin/clavulanic acid and ampicillin/ sulbactam in pharmaceutical formulations for injections" J. Pharm. Biomed. Anal, 2002., 29(1-2), 75-81,.

10. Pasamontes, A., Callao, M.P., "Sequential injection analysis for the simultaneous determination of clavulanic acid and amoxicillin in pharmaceuticals using second-order calibration" Anal Sci. 2006, 22(1), 131-135,.

11. El Walily, A.F., Gazy, A.A., Belal, S.F., Khamis, E.F., "Selective spectrofluorimetric determination of phenolic beta-lactam antibiotics through the formation of their coumarin derivatives" J. Pharm. Biomed. Anal, 1999.,20(4), 643-653,

12. Cao, W., Yang, J.H., Sun, C.X., Chen, Y.J., Gao, Q.F., "Flow injection chemilumine scence determination of amoxycillin using 
potassium permanganate and formaldehyde system" Luminescence, 2005., 20(1), 20-24,

13. Li, Y., Tang, Y., Yao, H., Fu, J., "Determination of ampicillin and amoxycillin by flow injection chemiluminescence method based on their enhancing effects on the luminol-periodate reaction" Luminescence, 2003., 18(6), 313317 ,

14. Li, Y., Lu, J., "Chemiluminescence flowinjection analysis of beta-lactam antibiotics using the luminol-permanganate reaction" Luminescence, 2006, 21(4), 251-255,.

15. Fernandez-Gonzalez, A., Badia, R., DiazGarcia, M.E., "Comparative study of the micellar enhanced spectrophotometric determination of (3-lactamic antibiotics by batch and flow injection analysis using a multisimplex design" J. Pharm. Biomed. Anal, 2002., 29(4), 669-679,

16. Sun, Y., Tang, Y., Yao, H., Li, Y., "Flow injection chemiluminescence analysis of some penicillins by their sensitizing effect on the potassium permanganate-glyoxal reaction" Anal Sci., 2005. 21(4), 457-460,

17. Garcia, M.S., Sanchez-Pedreno, C, Albero, M.I., Rodenas. V., "Determination of ampicillin or amoxycillin in pharmaceutical samples by flow injection analysis" J. Pharm. Biomed. Anal, 1994., 12(12), 1585-1589,

18. Kapetanovic, V., Veselinovic, D., "Determination of the $\mathrm{Ni}(\mathrm{II})$ - Amoxycillin couple by derivative polarography" Archiv der Pharmazie, 1988., 321, 559-560,

19. Uslu, B., Biryol, L, "Voltammetric determination of amoxicillin using a poly $(\mathrm{N}$ vinyl imidazole) modified carbon paste electrode" J. Pharm. Biomed. Anal,1999., 20(3), 591-598,

20. Z. Zhang, D.P. Grover, J.L. Zhou, Monitoring
Pharmaceuticals residues in sewage effluents, In: Handbook of water purity and quality, Ed.: Satinder Ahuja, Academic Press - Elsevier, Amsterdam. 2009.,315-342,

21. T.A. Ternes, A. Joss, H. Siegrist, Scrutinizing pharmaceuticals and personal care products in wastewater treatment, Environ. Sci. Technol. 2004 ,38 392A-399A.

22. M. Kobya, E. Demirbas, A. Dedeli, M.T. Sensoy, Treatment of rinse water from zinc phosphate coating by batch and continuous electrocoagulation processes, J. Hazard. Mater. 2010,173 326-334.

23. K. Chithra, N. Balasubramanian, modeling electrocoagulation through adsorption kinetics, J. Model. Simul. Systems 2010,1 124-130.

24. K. Bensadok, S. Benammar, F. Lapicque, G. Nezzal, Electrocoagulation of cutting oil emulsions using aluminium plate electrodes, J. Hazard. Mater. 2008 ,152 423-430.

25. M. Bayramoglu, M. Kobya, O.T. Can, M. Sozbir, Operating cost analysis of electrocoagulation of textile dye wastewater, Sep. Purif. Technol. 2004 , 37 117-125.

26. N. Balasubramaniana, T. Kojima, C.A. Basha, C. Srinivasakannan, Removal of arsenic from aqueous solution using electrocoagulation, J. Hazard. Mater. 2009, 167 966-969.

27. Y.S. Ho, G. McKay, the kinetics of sorption of divalent metal ions onto sphagnum moss peat, Water Res. 200034 735-742.

28. O. Ajouyed, C. Hurel, M. Ammari, L. Ben Allal, N. Marmie, Sorption of $\mathrm{Cr}(\mathrm{VI})$ onto natural iron and aluminum (oxy)hydroxides: Effects of $\mathrm{pH}$, ionic strength and initial concentration, Journal of Hazardous Materials, 174 616-622. 